\title{
Multiobjective Structure Topology Optimization of Wind Turbine Brake Pads Considering Thermal-Structural Coupling and Brake Vibration
}

\author{
S. Zhang $\mathbb{D}^{1},{ }^{1}$ J. Yin ${ }^{D},{ }^{1}$ Y. Liu ${ }^{D},{ }^{1}$ Z. Sha ${ }^{D},{ }^{1}$ F. Ma ${ }^{D},{ }^{1}$ Y. Wang, ${ }^{2}$ and B. Rolfe ${ }^{2}$ \\ ${ }^{1}$ School of Mechanical Engineering, Dalian Jiaotong University, Dalian, 116028, China \\ ${ }^{2}$ School of Engineering, Deakin University, Geelong, VIC 3220, Australia \\ Correspondence should be addressed to Y. Liu; liuyu_ly12@126.com
}

Received 21 May 2018; Accepted 31 July 2018; Published 9 August 2018

Academic Editor: Rafael Morales

Copyright (c) 2018 S. Zhang et al. This is an open access article distributed under the Creative Commons Attribution License, which permits unrestricted use, distribution, and reproduction in any medium, provided the original work is properly cited.

Brake pads of disc brake play an important role in the stable braking process of a large-megawatt wind turbine. There is always vibration, screaming, and severe nonuniform wear under the effect of both retardation pressure and friction. To solve these issues, this article aims to find a new structure of the brake pads to improve brake performance. A multiobjective structure topology optimization method considering thermal-structural coupling and brake vibration is carried out in this article. Based on topology optimization method of Solid Isotropic Microstructures with Penalization (SIMP), the compromise planning theory is applied to meet the stiffness requirement and vibration performance of brake pads. Structure of brake pads is optimized, and both the stiffness and vibration performance of brake pads are also improved. The disadvantages of single-objective optimization are avoided. Thermal-structural coupling analysis is tested with the actual working conditions. The results show that the new structure meets the stiffness requirement and improves the vibration performance well for the large-megawatt wind turbine. The effectiveness of the proposed method has been proved by the whole optimization process.

\section{Introduction}

Brake pads are an important component of the brake system for large-megawatt wind turbine's working stability. Brake pads used in large-megawatt wind turbine are shown in Figure 1 . When braking, the brake pad-disc contact generates large amounts of heat with retardation pressure and friction. The wear of the brake pad-disc is the most common failure in brake systems [1]. In the process of braking, due to the uneven contact of the brake pad-disc, the actual contact area is far less than the nominal contact area. And contact discontinuities causing uneven distribution of contact surface temperature lead to thermal deformation of the disc, which directly affects the contact state and contact stress and further impacts the input intensity of friction heat conversely. This coupling behavior leads to the thermoelastic instability (TEI) and then causes the brake vibration and noise [2]. The braking process can be described as a friction-heat-vibration coupled phenomenon, which brings a lot of issues influencing the brake performance as follows:

(1) The buckling deformation of brake pads generated by retardation pressure and friction

(2) The thermal deformation of brake pads caused by the heat generated in the braking process

(3) The vibration and screaming caused by the uneven wear of brake pad-disc [3].

Due to the issues above, the braking performance of the large-megawatt wind turbine is greatly reduced.

Extensive research in the following fields has been carried out on key technologies of the brake pad-disc.

In the temperature and thermal stress field, Jaeger developed Bolk's theory demonstrated and proposed the mathematical model of the rectangular mobile heat source on the semi-infinite surface $[4,5]$. Wu et al. presented a 


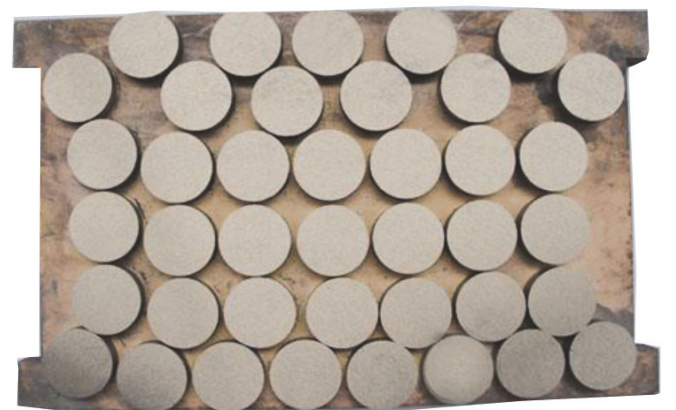

Figure 1: Brake pads used in the large-megawatt wind turbine.

methodology for the modeling of the transient thermal behavior of the disc brake of the vehicles through finite element methods [6]. Yevtushenko et al. performed a numerical simulation of frictional heating in a disc brake of a typical passenger vehicle based on the equation of motion and the boundary value problem of heat conduction. The influences of temperature-dependent coefficient of friction on the sliding velocity, braking time, braking distance, and thermomechanical wear were studied [7]. Aiming to provide a better understanding of thermal phenomena occurring in a sliding contact under tribological solicitation, Sellami et al. proposed a numerical model of pad-on-disc tribometer. The method used allowed the sequential estimation of the thermal boundary conditions by minimizing an error function between numerical and experimental temperature values [8]. Leila et al. finished the thermomechanical modeling of cracked brake disc. It was found that the main stress during braking is due to the high temperature variations induced by friction between the pads and the disc, and the numerical analysis by FEM of thermal stress distribution in disc thickness caused by heat-flux distribution was studied [9].

In the vibration and screaming field, Fu et al. measured the friction and wear properties of particle-reinforced cooper matrix composites fabricated by powder using friction tester and 1:1 test bench [10]. Timur et al. made a range of tests on brake pads with different materials continually undergoing braking during 300s process [11]. Bryant et al. measured the pads vibration under dynamic squeal conditions using a laboratory dynamometer to study a highly complex noise mechanism [12]. Dmitriev et al. analyzed the frictional behavior at local contacts in an automotive brake system on the basis of computer simulation by movable cellular automata method [13]. Liew et al. studied the tribological properties difference of potentially new designed noncommercial brake pads materials with and without asbestos under various speed and nominal contact pressure [14]. Kahraman et al. modeled and predicted the tribological behavior of the automotive brake pads using response surface methodology [15]. Singh et al. fabricated and characterized the physical, mechanical, and tribological properties of cement kiln dust (CKD) filled with different resin based brake pads formulations [16]. Hu et al. developed a 7-degree-of-freedom (DOF) vibration model of a fixed-caliper disc brake system based on the Stribeck effect to study the effects of braking conditions, such as disc rotational speed and brake pressure on brake noise. Finally, the numerical calculation results showed that the brake noise increased with an increasing braking force and a decreasing braking speed [17]. To solve the issue of automotive brake noise, Jung et al. found the relationship between patterned surfaces and brake squeal through the numerical methods, and it was found that the cross-drilled machining patterns were concluded to be an influential factor for in-plane mode frequency while the slotted patterns had more leverage for out-of-plane mode frequency [18].

In the research field of brake pads structure optimization, Zhou et al. optimized the structure of brake pads based on coefficient of variation. It was found that the unevenness of brake decreased by $46.82 \%$ while the coefficient of variation reduced by $20.91 \%$, and both the average contact pressure and contact area increased [19]. Wang et al. established the relationship between brake pads structure and distributions of temperature and thermal stress on brake disc using ABAQUS finite element software. Structure optimization was conducted on brake pads composed of 5 or 7 circular friction blocks. The results showed that, with the same overall contact area of friction pair, an appropriate brake pads structure can make the friction energy be distributed evenly and optimized brake pads of 5 friction blocks lowered the peak temperature of the corresponding brake disc by $4.9 \%$ and reduced the highest stress by $10.7 \%$ [20]. Sha et al. optimized the largemegawatt wind turbine brake pads structure considering only retardation pressure and friction. The volume of the brake pads decreased by $28.6 \%$ and using ratio of copper-base powder metallurgy material was promoted [21]. Based on Sha's result, Zhang et al. considered the thermal-structural coupling, and the optimized brake pads showed that much more material is needed to be maintained to conduct the heat generated in the braking process. Therefore, Zhang found that how the thermal-structural coupling influenced on structure optimization of the large-megawatt wind turbine brake pads [22]. Han et al. carried out a coupled thermomechanical analysis of the brake disc-pad in vehicle brake system, and it was found that the nonuniform contact pressure distribution on the brake pads was a major cause of uneven wear. Finally, the shape optimization of the brake pads was performed to reduce the uneven wear [23]. Pan et al. designed brake pads with different structural shapes, and the influence on the stability of the brake system was analyzed. Pan found that the design of the 3-layer structure and the slotting design of the brake pad can effectively reduce the occurrence of the brake squeal [24].

However, in order to find the frequency influence on the structure design of brake pads, this article develops a multiobjective structure topology optimization method considering thermal-structural coupling and brake vibration. A three-dimensional (3D) model of the brake pads is established. The heat absorbed by the brake pads is calculated and the thermal-structural coupling analysis is finished to receive the deformation restriction. Moreover, the former 4 modes are received by the modal analysis. Finally, the optimized brake pads meeting the static and dynamic requirements is obtained. The multiphysics and multiobjective optimization 
TABLE 1: Experimental data of braking process in large-megawatt wind turbine brake.

\begin{tabular}{lcccc}
\hline $\begin{array}{l}\text { Original revolution } n \\
(\mathrm{r} / \mathrm{min})\end{array}$ & $\begin{array}{c}\text { Diameter of the brake } \\
\operatorname{disc} d(\mathrm{~mm})\end{array}$ & $\begin{array}{c}\text { Retardation pressure } \\
F(\mathrm{~N})\end{array}$ & Braking time $t_{\mathrm{e}}(\mathrm{s})$ & $\begin{array}{c}\text { Braking torque } M \\
(\mathrm{Nm})\end{array}$ \\
\hline 1000 & 800 & 17000 & 19.16 & 3500 \\
\hline
\end{tabular}

method proposed in this article offers some insights into the optimization of other similar structures.

\section{Mechanical Property Analysis of Brake Pads}

\subsection{Thermal-Structural Coupling Analysis}

2.1.1. Assumptions. Model of the brake pads needs to be simplified before the analysis of topology optimization considering thermal-structural coupling. To make the result converge rapidly, some basic assumptions are made as follows:

(1) The material of brake pads is considered as isotropic and the sliding friction coefficient is constant during the sliding process.

(2) The contact surface of the brake disc/pad is an ideal flat plane and the instantaneous temperature of each contact point pair on the contact surface is equal during the braking process.

(3) During the braking process, all the friction energy is converted into heat.

2.1.2. Calculation of Heat-Flow Density. During the braking process, large amount of heat is generated. The brake performance is largely influenced by the thermal deformation. Experimental data of the braking process we collected are shown in Table 1.

According to the law of conservation of energy and the friction heat generation principle, the friction heat $Q$ is given as

$$
Q=W=f s=\mu F \int_{0}^{t_{e}} v(t) \mathrm{d} t
$$

where $W$ is the friction work, $f$ is the friction, $s$ is the braking distance, $\mu$ is the frictional coefficient between the brake disc and the brake pads, $F$ is the retardation pressure, $v(t)$ is the speed of the brake disc at any time during braking, and $t_{e}$ is the braking time. The friction heat $Q$ also can be expressed as

$$
Q=\Phi t_{e}=q A t_{e}
$$

where $q$ is the heat-flow density, $\Phi$ is the heat flux, and $A$ is the contact area of the brake pad-disc. The heat-flow density distribution ratio $r$ is given as

$$
r=\frac{q_{d}}{q_{p}}=\sqrt{\frac{\lambda_{d} C_{d} \rho_{d}}{\lambda_{p} C_{p} \rho_{p}}}
$$

where $q_{d}$ is the heat-flux density of the brake disc and $q_{p}$ is that of the brake pads, $\lambda_{d}$ is the heat conduction of the brake disc, and $\lambda_{p}$ is that of the brake pads, $C_{d}$ is the specific heat capacity of the brake disc, and $C_{p}$ is that of the brake pads, and $\rho_{d}$ is the density of the brake disc and $\rho_{p}$ is that of the brake pads. The thermal equation is expressed as

$$
\lambda_{p} \frac{\partial T_{p}}{\partial z}=\lambda_{c}\left(T_{d}-T_{p}\right)+q_{p}
$$

where $T_{d}$ is the transient temperature of the brake disc and $T_{p}$ is that of the brake pads. According to Assumption (2), $T_{p}=T_{d}$, which means the temperature on the contact surface is the same. Therefore, (4) can be simplified as

$$
\lambda_{p} \frac{\partial T_{p}}{\partial z}=q_{p}
$$

According to the derivation of the heat-flux density as well as the natural heat conduction between pads and disc, the temperature rise $T_{p}$ is given as

$$
T_{p}=\frac{(1-\omega) \mu p(x, y, t) v(x, y, t) z}{\lambda_{p}}+T_{0}
$$

where $\omega$ is the weight coefficient of the heat-flux density transferred into the brake disc, $p(x, y, t)$ is the specific pressure of the contact surface on the brake pads, $v(x, y, t)$ is the relative speed between the brake disc and the brake pads, and $T_{0}$ is the original environment temperature. During the structure topology optimization considering thermalstructural coupling, the equivalent strain and stress are needed. The thermal stress $[\sigma]$ is expressed as

$$
[\sigma]=[D]([\varepsilon]-[\Delta \varepsilon])
$$

where $[D]$ is the elastic strain matrix, $[\varepsilon]$ is the strain matrix, and $[\Delta \varepsilon]$ is the temperature strain matrix caused by the temperature change. In the $3 \mathrm{D}$ space, the temperature strain matrix $[\Delta \varepsilon]$ is expressed as

$$
[\Delta \varepsilon]=\alpha\left(T_{p}-T_{0}\right)\left[\begin{array}{llllll}
1 & 1 & 1 & 0 & 0 & 0
\end{array}\right]^{\mathrm{T}}
$$

where $\alpha$ is the coefficient of thermal expansion. Combine (7) and (8),

$$
[\sigma]=[D]\left([\varepsilon]-\alpha\left(T_{p}-T_{0}\right)\left[\begin{array}{llllll}
1 & 1 & 1 & 0 & 0 & 0
\end{array}\right]^{\mathrm{T}}\right)
$$

Besides, the thermal stress along the thickness direction of the brake pads $\sigma_{z}$ is given as follows:

$$
\sigma_{z}=D\left(\varepsilon_{z}-\Delta \varepsilon_{z}\right)
$$

where $\Delta \varepsilon_{\mathrm{z}}$ is the temperature strain and $\varepsilon_{\mathrm{z}}$ is the strain. Finally, $\sigma_{\mathrm{z}}$ can be expressed as follows:

$$
\sigma_{z}=D\left(\varepsilon-\alpha \frac{(1-\omega) \mu p(x, y, t) v(x, y, t) z}{\lambda_{p}}\right)
$$




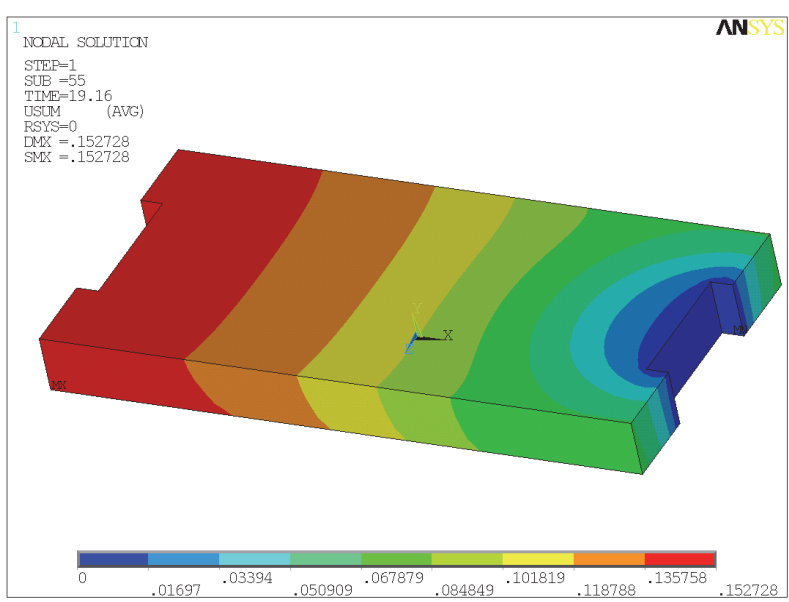

(a) Equivalent strain

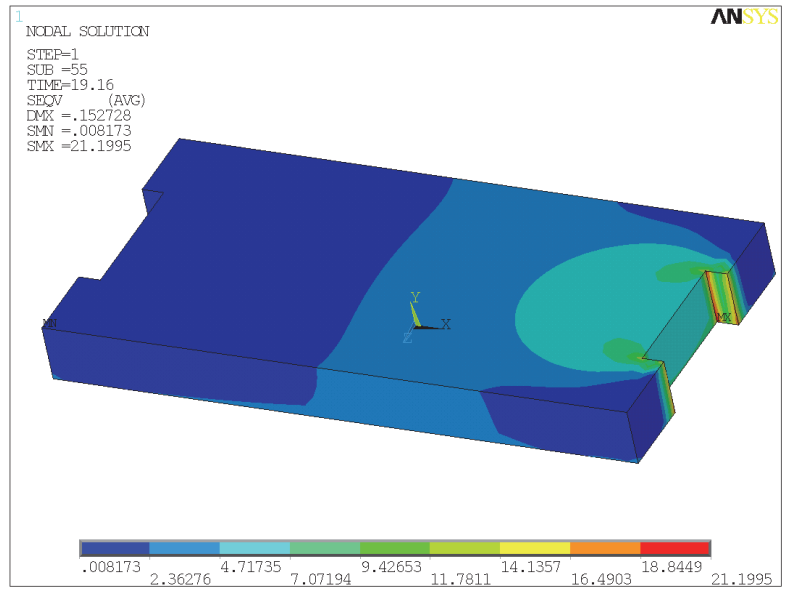

(b) Equivalent stress

FIGURE 2: Contours of equivalent strain and stress after thermal-structural coupling analysis of the brake pads.

From the thermal stress along the thickness direction of the brake pads, $\sigma_{\mathrm{z}}$ can be calculated through (11). $\sigma_{\mathrm{z}}$ is the stress that can make the brake pads deform significantly. Besides, it can be used as a kind of imposed load in the topology optimization method developed in this paper. It will restore the result of the thermal-structural coupling analysis.

\subsubsection{Thermal-Structural Coupling Analysis Result. With the} ANSYS 15.0 finite element analysis software, the thermal analysis is finished, then, in the static structure analysis, the result of the thermal analysis can be seen as a kind of thermal load. Finally, contours of equivalent strain and stress after thermal-structural coupling finite element analysis of the brake pads are shown in Figure 2.

Based on the basic assumptions, the contact surface between pads and disc is ideal flat plane, which means that all the heat generated by the friction is converted into temperature rise. And the heat conducts along the thickness direction, the maximum temperature appears in the contact surface, which is more than $500^{\circ} \mathrm{C}$. The temperature decreases along the thickness direction, and the minimum temperature, about $70^{\circ} \mathrm{C}$, appears on the top of the brake pads. In Figure 2(a), the maximum equivalent strain appears at the entry of the friction (on the left of Figure 2(a)) and the minimum appears at the exit of the friction (on the right of Figure 2(a)). During braking, with the combined effect of retardation pressure and friction, the brake pad is pushed into the exit of the friction, which makes the groove of the exit as a fulcrum, and the brake pad becomes a cantilever. The farthest part from the fulcrum has the maximum equivalent strain, which is $0.15 \mathrm{~mm}$. In Figure 2(b), the equivalent stress of most of the brake pads is distributed equally. But at the exit of the friction, especially at the significant dimension-change part, the concentration of the equivalent stress is obvious, which even can be $4-5$ times greater than that of other parts, which shows the influence of heat indirectly.

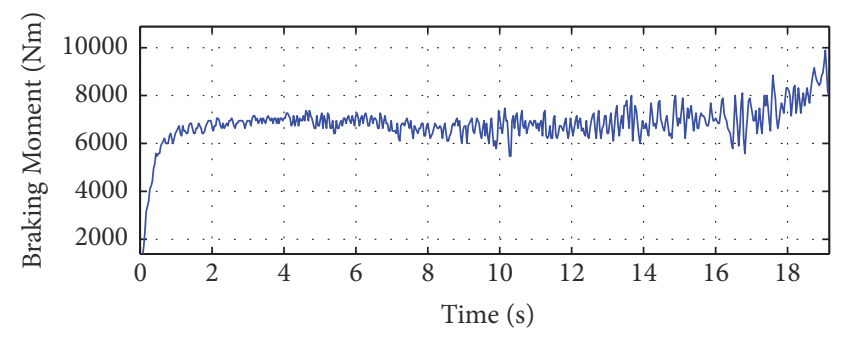

FIGURE 3: Braking process of wind turbine brake.

\subsection{Dynamic Behavior Analysis of Brake Pads}

2.2.1. Braking Process Analysis of Wind Turbine Brake. During the braking process, the brake disc fixed on the high-speed shaft rotates together with the large-megawatt wind turbine. Vibrations with various frequencies appear in the braking system because of the deformation and the uneven wear of the brake pads. It is of great significance to improve the performance and reliability of the brake by reducing the vibration and screaming, which also increases the stability of the structure.

To resist the vibration and screaming of the brake, the frequencies of vibration and screaming need to be obtained through test. The braking moment of the large-megawatt wind turbine is also tested in this paper. Figure 3 shows the braking moment versus braking time. After $19.16 \mathrm{~s}$, the wind turbine turns into stop. During braking, at the contact of the brake disc and the brake pads, the braking moment rises to $6000 \mathrm{Nm}$ in the first second. After that, it fluctuates around $7000 \mathrm{Nm}$ to $8000 \mathrm{Nm}$. The maximum braking moment reaches $10000 \mathrm{Nm}$ when the turbine stops.

To find out the vibration frequency, the Fast Fourier Transform (FFT) method is adopted to transform Figure 3 


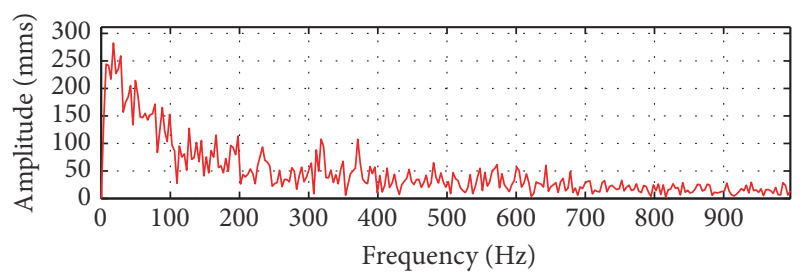

FIGURE 4: Main vibration frequencies in braking process.

from time domain into frequency domain. Considering the signal may mostly distribute in the low frequency area, it needs square processing to change it into energy signal, the transformation result is shown in Figure 4.

In Figure 4, the horizontal axis is frequency, and the vertical axis is amplitude. All the vibration frequencies during braking are distributed within the range of $0-1000 \mathrm{~Hz}$, which is called shaking and chattering. Most amplitudes in Figure 4 are distributed in the range from 0 to $400 \mathrm{~Hz}$, which means the vibration style of the wind turbine brake belongs to braking shaking. And the maximum energy appears at the frequency of $17.66 \mathrm{~Hz}$.

Because the screaming frequency is too high, the test only captured the vibration signal. A completed screaming test of disc brake can be found in [25], where a sound sensor, like a microphone, was placed near the friction area, and the screaming signal was captured by the sound sensor and then turned into electronic signal. Finally, the test result showed that the screaming frequency of the brake system is about $2100 \mathrm{~Hz}$. And the screaming is mainly caused by the resonance of brake pads and disc contact. If the structure of the brake pads can be modified, then the inherent frequency of the brake pads can be changed as well. Therefore, the sympathetic vibration can be finally prevented to avoid the screaming. To make the brake pads designed in this paper more widely used, the natural frequency of the brake pads still should avoid the screaming frequency. In conclusion, while designing the structure of the brake pads, the natural frequency should avoid both the brake shaking and chattering within 0-400 $\mathrm{Hz}$ and the braking screaming with the frequency near 2100 $\mathrm{Hz}$.

2.2.2. Modal Analysis of Brake Pads. The modal analysis is conducted by using the HyperWorks 11.0 software, which provides the former 4 modes shown in Figure 5. The frequencies of the former 4 modes are $796.17 \mathrm{~Hz}, 1629.39 \mathrm{~Hz}, 1872.54$ $\mathrm{Hz}$, and $2684.55 \mathrm{~Hz}$, respectively. The vibration modes of the former 4 modes are curving along Y-axis, curving along $\mathrm{X}$-axis, warping along $\mathrm{Y}$-axis, and warping along $\mathrm{X}$-axis, respectively.

As seen from the results, the frequencies of the former 4 modes are higher than the frequency of braking shaking and chattering, but the frequencies of the third and fourth mode are very close to the screaming frequency.

\section{Multiobjective Structure Topology Optimization of Brake Pads considering Thermal-Structural Coupling and Vibration}

3.1. Mathematic Model of Topology Optimization. According to the finite element theory, the equivalent stress of every element $\{\sigma\}$ in the structure can be expressed as

$$
\{\sigma\}=[D]\{\varepsilon\}=[S]\{\delta\}_{e}=[D][B]\{\delta\}_{e}
$$

where $[S]$ is the equivalent stress matrix of every element, $[B]$ is the strain matrix, and $\{\delta\}_{e}$ is the node displacement. The stiffness matrix of every element $[K]$ can be expressed as follows:

$$
[K]=\iint_{A}[B]^{\mathrm{T}}[D][B] t \mathrm{~d} x \mathrm{~d} y
$$

The element displacement $\left\{U_{i}\right\}$ can be deduced by the equivalent stress of the element:

$$
\left\{U_{i}\right\}=[N][S]^{-1}\{\delta\}_{e}
$$

where $[N]$ is the shape function of the element; combining (12), (13), (14), the static stiffness objective function considering thermal-structural coupling is expressed as

$$
\begin{gathered}
\min C_{H}(x)=\sum_{i=1}^{N} x_{i}^{p} \Delta E\left\{U_{i}\right\}^{\mathrm{T}}\left[K_{i}\right]\left\{U_{i}\right\}=\sum_{i=1}^{N} x_{i}^{p} \Delta E \\
\cdot\left\{[N][S]^{-1}\{\sigma\}\right\}^{\mathrm{T}} \iint_{A}[B]^{\mathrm{T}}[D][B] t \mathrm{~d} x \mathrm{~d} y \\
\cdot\left\{[N][S]^{-1}\{\sigma\}\right\}
\end{gathered}
$$

With the method of variable density structure topology optimization based on SIMP, combined with (15), the static and dynamic multiobjective function $H_{H}(x)$ considering thermal-structural coupling is expressed as

$$
\begin{aligned}
& \min H_{H}(x) \\
& \quad=\sqrt{\omega_{1}^{2}\left[\frac{C_{H}(x)-C_{H \min }}{C_{H \max }-C_{H \min }}\right]^{2}+\omega_{2}^{2}\left[\frac{F_{\max }-F(x)}{F_{\max }-F_{\min }}\right]^{2}}
\end{aligned}
$$

where $x$ is the relative density of every element, which is the design variable, $C_{H}(x)$ is the flexibility of the optimized brake pads, which is the static objective, $C_{H \min }$ is the minimum flexibility and $C_{H \max }$ is the maximum, $F(x)$ is the natural frequency of the optimized brake pads, which is the dynamic objective, $F_{H \min }$ is the minimum natural frequency and $F_{H \max }$ is the maximum, $\omega_{1}$ is the weight coefficient of the static objective, and $\omega_{2}$ is the weight coefficient of the dynamic objective, which meets $\omega_{1}+\omega_{2}=1$. To compare the influence of each objective accurately, $\omega_{1}=\omega_{2}=0.5$ is set.

To ensure the structure of the brake pads not to be destroyed by the coupled effect of heat, retardation pressure, and friction, the optimized brake pads should meet the maximum stiffness of the original one, and to ensure the brake 
TABLE 2: Comparison of the primary four frequencies.

\begin{tabular}{lccc}
\hline Frequency number & Before optimization $(\mathrm{Hz})$ & After optimization $(\mathrm{Hz})$ & Amplitude of variation(\%) \\
\hline 1 & 796.17 & 775.43 & -2.60 \\
2 & 1629.39 & 1689.39 & +3.68 \\
3 & 1872.54 & 1706.03 & -8.89 \\
4 & 2684.55 & 3040.30 & +13.25 \\
\hline
\end{tabular}
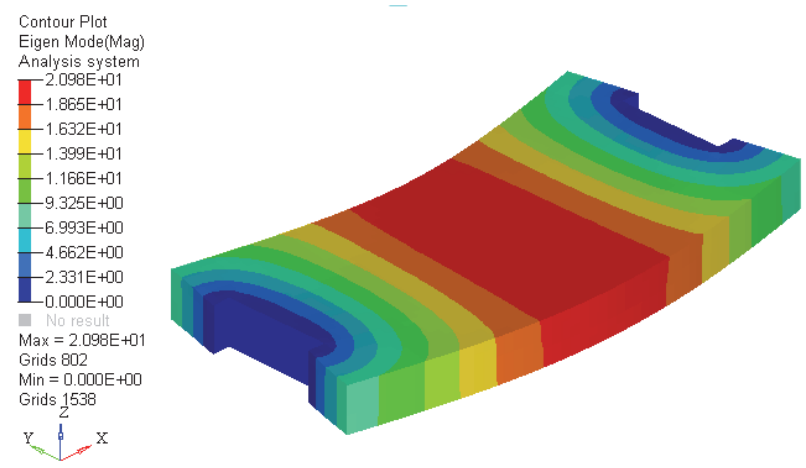

(a) The first mode
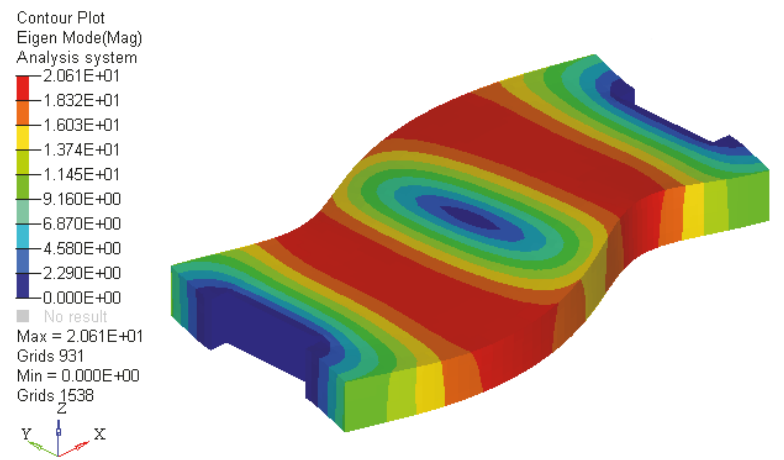

(c) The third mode
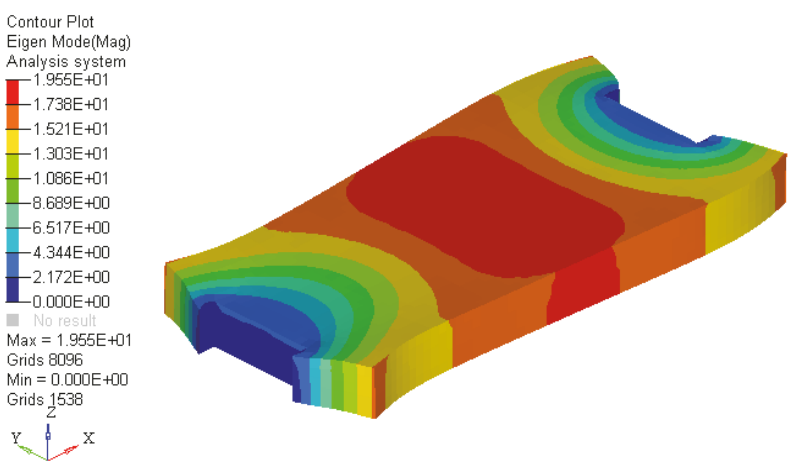

(b) The second mode

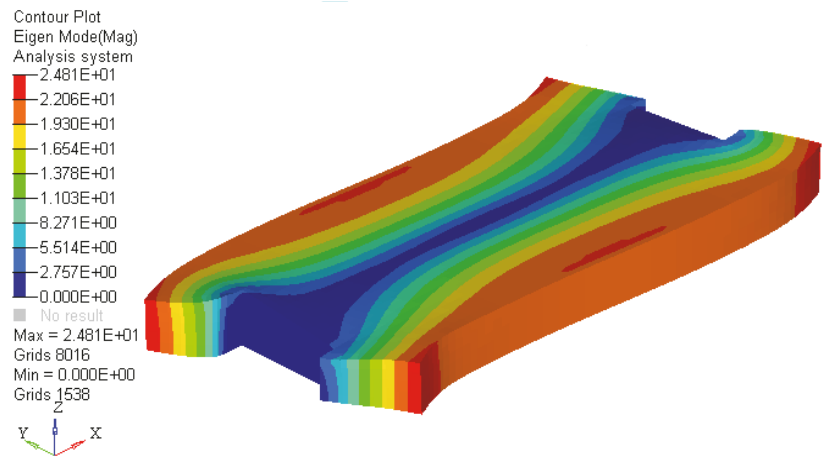

(d) The fourth mode

FIGURE 5: Results of modal analysis on wind turbine brake pads.

performance of the wind turbine brake, the deformation of the brake pads should be constrained to ensure a certain contact area of the brake disc and the brake pads, so that the maximum equivalent strain of the brake pads, especially the maximum equivalent strain in the area of the braking pressure, should be less than $0.15 \mathrm{~mm}$. Meanwhile, to avoid the resonance with braking shaking and chattering, as well as braking screaming, the third mode frequency should be reduced and the fourth mode frequency should be lifted. Besides, to make the optimized brake pads display clearly in the result, the volume fraction of the optimized brake pads is limited to no more than $80 \%$.

3.2. Result of Topology Optimization. In the HyperWorks software, the minimum flexibility $C_{H \min }$ and the maximum flexibility $C_{H \max }$ and the minimum natural frequency $F_{H \min }$ and the maximum natural frequency $F_{H \max }$ in (16) can be calculated as $C_{H \min }=3.426 \times 10^{2}, C_{H \max }=3.42654 \times 10^{3}$, $F_{H \min }=1.76, F_{H \max }=5.762 \times 10^{3}$. Substitute all the results into
(16), after 55 iterations in HyperWorks, the topology optimization is finished. Modal analysis shows that the mode frequency of the optimized brake pads changes. The frequencies of the former 4 modes are $775.43 \mathrm{~Hz}, 1689.39 \mathrm{~Hz}, 1706.03$ $\mathrm{Hz}$, and $3040.30 \mathrm{~Hz}$, respectively. The topology structure of the optimized brake pads is shown in Figure 6, and the comparison of the primary four frequencies is shown in Table 2.

From Table 2, the frequency of the first mode is 775.43 $\mathrm{Hz}$, which is higher than the frequency of braking shaking and chattering, and the third mode is $1706.03 \mathrm{~Hz}$, which is lower than the original one by $8.89 \%$, and the fourth mode is $3040.30 \mathrm{~Hz}$, which is higher than the original one by $13.25 \%$. The result shows that both the third and the fourth modes are far away from the frequency of braking screaming, which means the optimized brake pads meet the requirement of the dynamic objective.

The area of element relative density in Figures 6(a) and $6(\mathrm{~b})$ is from 0 to 1 , which shows all the design area, but it is 


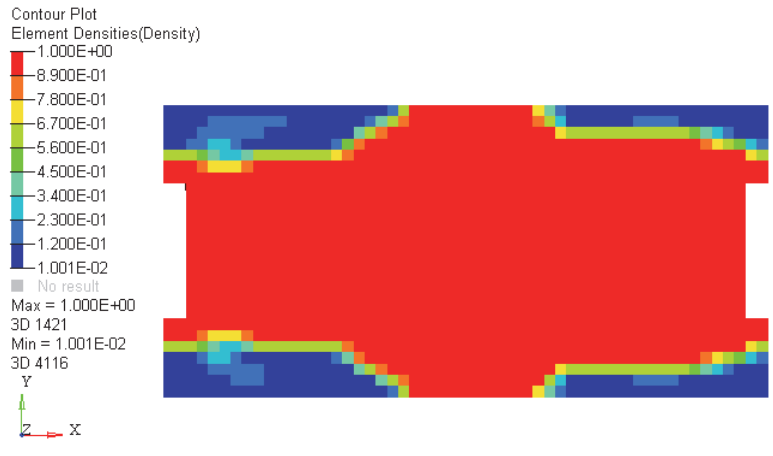

(a) Density $[0,1]$ (retardation pressure surface)

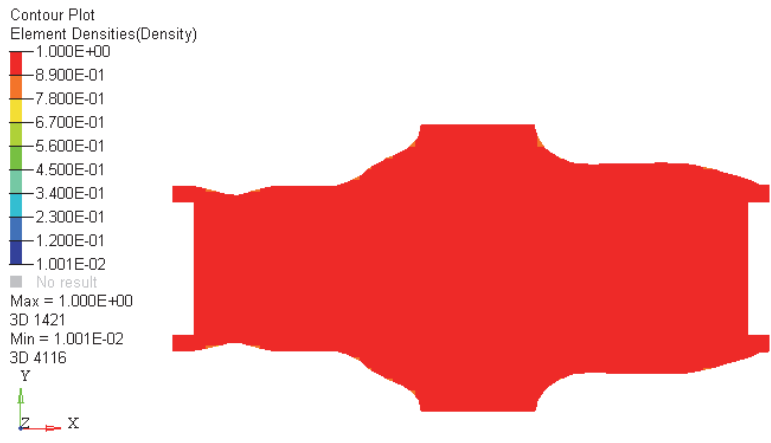

(c) Density $[0.6,1]$ (retardation pressure surface)

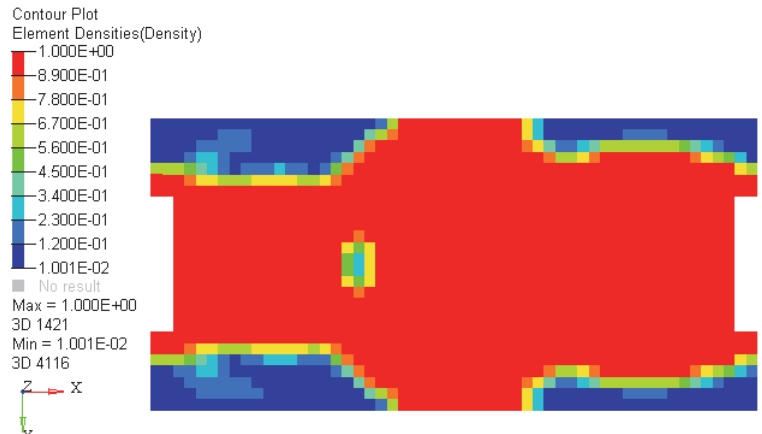

(b) Density $[0,1]$ (brake disc contact surface)

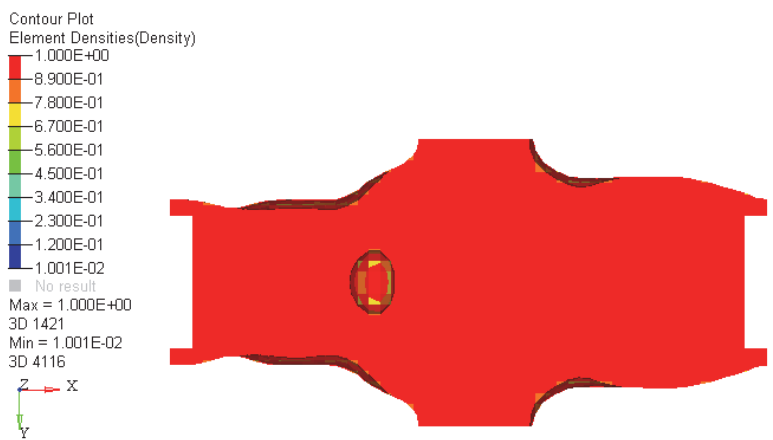

(d) Density $[0.6,1]$ (brake disc contact surface)

FIGURE 6: Density contours of brake pads after multiobjective structure topology optimization.

from 0.6 to 1 in Figures 6(c) and 6(d), in which the optimized structure of the brake pads can be seen. The retardation pressure surface is shown in Figures 6(a) and 6(c), and the contact surface between the brake disc and the brake pads is shown in Figures 6(b) and 6(d).

In Figures 6(a) and 6(c), the relative density of every element trends to be 0 or 1 perfectly, and the topology model of the brake pads can be seen very clearly. This means the mathematic model of multiobjective structure topology optimization of the brake pads considering thermal-structural coupling is very close to the actual working condition. In the topology model, materials on both sides along the radius direction of the brake pads deform easily, while the relative density of these elements tends to be 0 . With the combined effect of retardation pressure and friction, the width of the brake pads in the entry of the friction is smaller than that in the exit. The topology optimization considering thermal effect shows that most materials should be contained to conduct the heat generated during braking. In Figure 6(c), part of the material is deleted near the entry of the friction, forming an obvious oblong hole. The purpose of this hole is to meet the requirement of the dynamic objective to improve the dynamic performance of the brake pads. In Figures 6(b) and $6(\mathrm{~d})$, the area of relative density is shrunk, in which the topology model can provide evidence for the reconstruction of the brake pads.

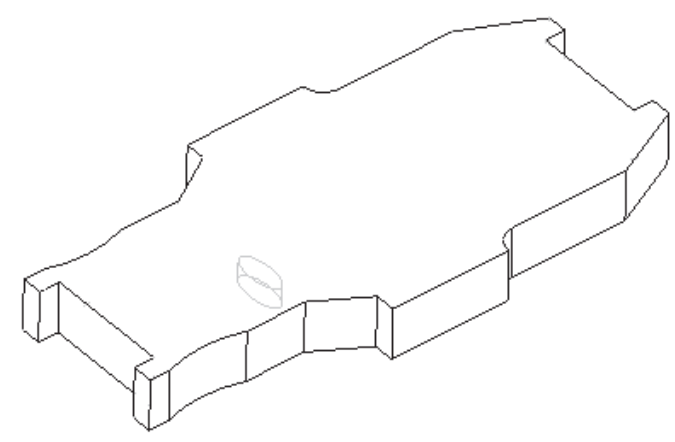

FIGURE 7: Reconstructed model of optimized brake pads.

\section{Reconstruction of Optimized Structure}

4.1. Reconstruction of Brake Pads. The outline of the reconstructed brake pads comes from the result of multiobjective topology optimization. By using the data tracing technology, the outline can be obtained directly as shown in Figure 7. This may not be the real brake pads, but the brake blocks can be distributed on the board according to this outline. The volume of the new structure is $77.12 \%$ of the original one.

4.2. Verification of Reconstructed Structure. The reconstructed structure is meshed. With the same load and 


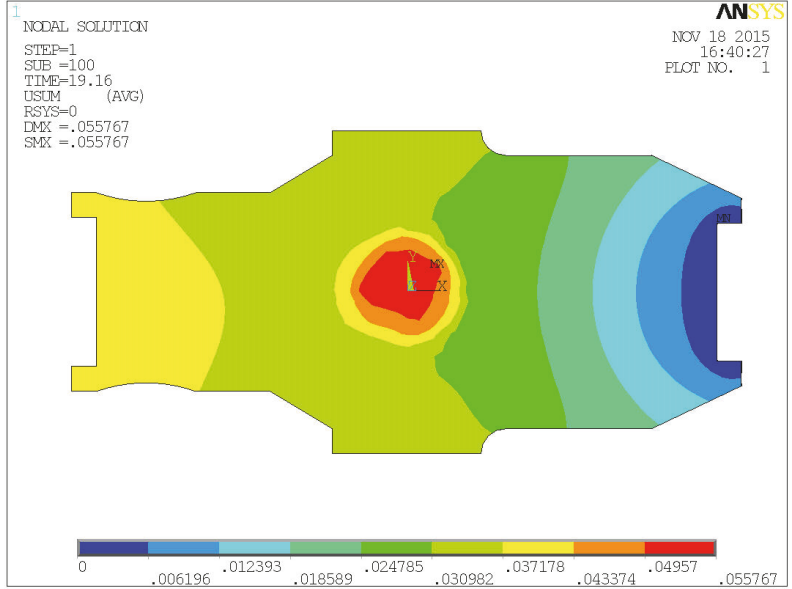

(a) Equivalent strain (retardation pressure surface)

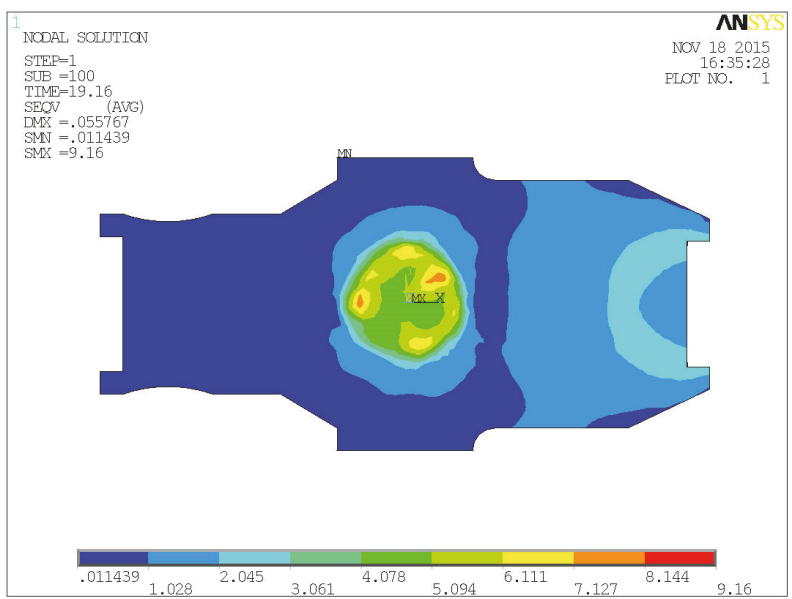

(c) Equivalent stress (retardation pressure surface)

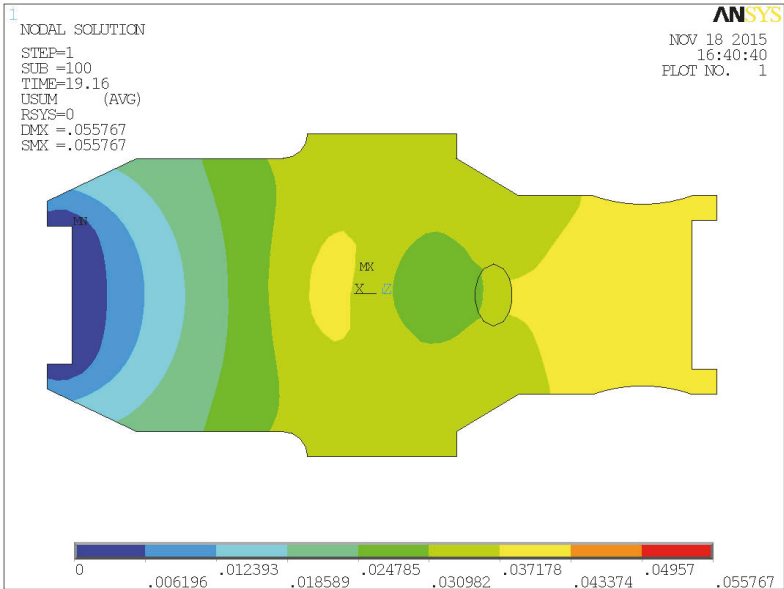

(b) Equivalent strain (brake disc contact surface)

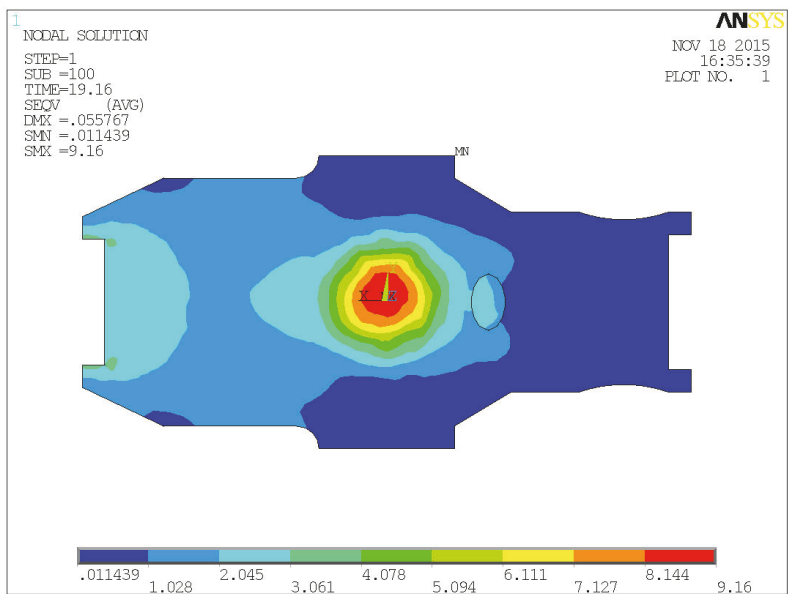

(d) Equivalent strain (brake disc contact surface)

Figure 8: Contours of equivalent strain and stress after verification of reconstructed model.

boundary condition as thermal-structural coupling analysis of the original brake pads, the thermal-structural coupling analysis of the reconstructed brake pads is finished by using ANSYS. The result contours are shown in Figure 8 .

In Figure 8, (a) and (b) show the equivalent strain, and the equivalent stress is shown in (c) and (d). There exists big difference on the retardation pressure surface and the brake disc contact surface, (a) and (c) show the retardation pressure surface, and (b) and (d) show the brake disc surface.

In the equivalent strain contour, the minimum equivalent strain appears at the exit of the friction. Because of the combined effect of retardation pressure and friction, the material is pushed towards the exit side, where the equivalent strain is almost 0 . And the equivalent strain becomes larger and larger from the exit of the friction to the entry. But the maximum equivalent strain appears at the top of the brake pads. With the effect of thermal-structural coupling, the maximum equivalent strain is $0.056 \mathrm{~mm}$. After the modal analysis of the reconstructed brake pads, the frequencies of the former 4 modes are $770.61 \mathrm{~Hz}, 1613.87 \mathrm{~Hz}, 1676.39 \mathrm{~Hz}$, and $2972.65 \mathrm{~Hz}$. Compared with the former 4 modes of the topology model, every frequency changes in different level. But the frequency of the first mode is still higher than the frequency of braking shaking and chattering. The frequencies of the third mode and the fourth mode are still far away from the frequency of braking screaming. All of these show that the reconstructed structure of the brake pads meets the requirement of the dynamic objective. Combined with the thermal-structural coupling analysis, the reconstructed structure of the brake pads meets the requirements of both stiffness and dynamic objectives which are the actual working conditions of the brake pads in large-megawatt wind turbine brake.

\section{Conclusions}

Inspired by the SIMP and the compromise planning theory, a new topological model is proposed for multiobjective optimization of the brake pads, which considers both the stiffness and vibration performance. The results show that (1) the established topological model using in thermal and 
structural fields provides theoretical foundation for applying topology optimization technology in multi-field coupling, and, through the brake pads optimization, accuracy of the method is tested; (2) multiobjective optimization objective including static stiffness objective and dynamic property objective based on the compromise planning theory is built, which avoids the disadvantages of single-objective optimization; (3) new structure of the brake pads in the large-megawatt wind turbine which meets the requirements of stiffness and braking vibration has been optimized with the established topological model with multiobjective optimization considering thermal-structural coupling, and the nonuniform wear, braking vibration, and screaming, as well as thermal deformation, are all improved. The volume of the new structure is $77.12 \%$ of the original one, which reduces weight and increases the use ratio of the brake pads.

\section{Data Availability}

The data used to support the findings of this study are available from the corresponding author upon request.

\section{Conflicts of Interest}

The authors declare that there are no conflicts of interest regarding the publication of this paper.

\section{Acknowledgments}

The authors gratefully acknowledge the financial support of National Natural Science Foundation of China (no. 51475066 and no. 51675075), Natural Science Foundation of Liaoning Province (no. 2015020114), and Outstanding Talent Project of Education Department of Liaoning Province (no. LR2015012).

\section{References}

[1] Y. Lin, L. Tu, H. Liu, and W. Li, "Fault analysis of wind turbines in China," Renewable \& Sustainable Energy Reviews, vol. 55, pp. 482-490, 2016.

[2] S. Zhang, J. Yin, Y. Liu et al., “Thermal-structural coupling analysis of brake friction pair based on the displacement gradient circulation method," Advances in Mechanical Engineering, vol. 10, no. 5, p. 168781401877381, 2018.

[3] Z. Wang and S. Liu, "Study on Synthesis Fault Diagnosis Strategy of the Brake System of Wind Turbine Based on Evidence Theory," in Applied Informatics and Communication, vol. 226 of Communications in Computer and Information Science, pp. 1825, Springer Berlin Heidelberg, Berlin, Heidelberg, 2011.

[4] H. Blok, "The flash temperature concept," Wear, vol. 6, no. 6, pp. 483-494, 1963.

[5] O. O. Evtushenko, E. H. Ivanyk, and N. V. Horbachova, "Analytic methods for thermal calculation of brakes (review)," Journal of Materials Science, vol. 36, no. 6, pp. 857-862, 2000.

[6] Y. Wu, H. Jin, Y. Li, Z. Ji, and S. Hou, "Simulation of temperature distribution in disk brake considering a real brake pad wear," Tribology Letters, vol. 56, no. 2, pp. 205-213, 2014.

[7] A. A. Yevtushenko and P. Grzes, "3D FE model of frictional heating and wear with a mutual influence of the sliding velocity and temperature in a disc brake," International Communications in Heat and Mass Transfer, vol. 62, pp. 37-44, 2015.

[8] A. Sellami, M. Kchaou, R. Elleuch, and Y. Desplanques, "Thermal analysis of pad-on-disc contact under tribological solicitations: a coupled numerical-experimental approach to identify surface temperatures and flow partition coefficient," Heat and Mass Transfer, vol. 52, no. 9, pp. 1923-1934, 2016.

[9] L. Khammar, M. S. Mecibah, and R. Zellagui, "Thermo mechanical modelling of cracked brake disc," UPB Scientific Bulletin, Series D: Mechanical Engineering, vol. 80, no. 1, pp. 171-180, 2018.

[10] R. Fu, B.-Y. Song, F. Gao, and X.-B. Yun, "Effect of friction conditions on friction properties of braking materials used for trains," Zhongguo Youse Jinshu Xuebao/Chinese Journal of Nonferrous Metals, vol. 18, no. 7, pp. 1223-1230, 2008.

[11] M. Timur and H. Kuşçu, "Heat transfer of brake pad used in the autos after friction and examination of thermal tension analysis," Mechanika, vol. 20, no. 1, pp. 17-23, 2014.

[12] D. Bryant, F. Solms, J. Fieldhouse et al., "nvestigation of Brake Pad Vibration Under Dynamic Squeal Conditions," International Journal of Rock Mechanics \& Mining Sciences, vol. 41, no. 6, pp. 915-925, 2012.

[13] A. I. Dmitriev and W. Österle, "Modeling of brake paddisc interface with emphasis to dynamics and deformation of structures," Tribology International, vol. 43, no. 4, pp. 719-727, 2010.

[14] K. W. Liew and U. Nirmal, "Frictional performance evaluation of newly designed brake pad materials," Materials and Corrosion, vol. 48, pp. 25-33, 2013.

[15] F. Kahraman and B. Sugözü, "Wear And Frictional Behaviours of Automotive Brake Pad Sliding Against GG 20 Cast Iron Counter Face," International Journal of Automotive Engineering and Technologies, vol. 5, no. 2, p. 71, 2016.

[16] Kang. JongHun and Lee. HyoungWoo, "he Development of Wind Turbine Brake by Finite Element Method," International Journal of Applied Engineering Research, vol. 11, no. 20, pp. 10294-10298, 2016.

[17] S. Hu and Y. Liu, "Disc Brake Vibration Model Based on Stribeck Effect and Its Characteristics under Different Braking Conditions," Mathematical Problems in Engineering, vol. 2017, 2017.

[18] T. Jung, Y. Hong, S. Park, C. Kim, Y. Hong, and C. Cho, "Numerical Study for Brake Squeal by Machining Patterns on Frictional Surface," International Journal of Automotive Technology, vol. 19, no. 2, pp. 281-289, 2018.

[19] B. J. Zhou, M. Z. Liu, Yuan. J. Z. et al., "Brake pad's structure optimization based on coefficient of variation," Machinery Design \& Manufacture, 2009.

[20] G. Wang and R. Fu, "Impact of brake pad structure on temperature and stress fields of brake Disc," Advances in Materials Science and Engineering, vol. 2013, 2013.

[21] Z. Sha, J. Yin, S. Zhang, Y. Liu, and F. Ma, "Structure Topology Optimization Design of Brake Pad in Large Megawatt Wind Turbine Disc Brake," in Proceedings of the First International Conference on Information Sciences, Machinery, Materials and Energy, Chongqing, China, April 2015.

[22] S. F. Zhang, J. Yin, Y. Liu, Z. H. Sha, and F. J. Ma, "Structure Topology Optimization of Brake Pad in Large- megawatt Wind Turbine Brake Considering Thermal- structural Coupling," in Proceedings of the 2016 2nd International Conference on Mechanical Engineering and Automation Science, ICMEAS 2016, Singapore, October 2016. 
[23] M. J. Han, C. H. Lee, T. W. Park, J. M. Park, and S. M. Son, "Coupled thermo-mechanical analysis and shape optimization for reducing uneven wear of brake pads," International Journal of Automotive Technology, vol. 18, no. 6, pp. 1027-1035, 2017.

[24] Gongyu Pan and Lei Chen, "Impact Analysis of Brake Pad Backplate Structure and Friction Lining Material on Disc-Brake Noise," Advances in Materials Science and Engineering, vol. 2018, Article ID 7093978, 9 pages, 2018.

[25] D. Jiang and D. Guan, "Study on disc brake squeal using closed-loop coupling model," Qinghua Daxue Xuebao/Journal of Tsinghua University, vol. 38, no. 8, pp. 88-91, 1998. 


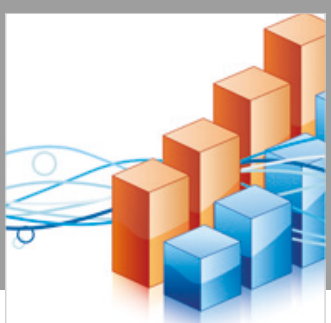

Advances in

Operations Research

\section{-n-m}
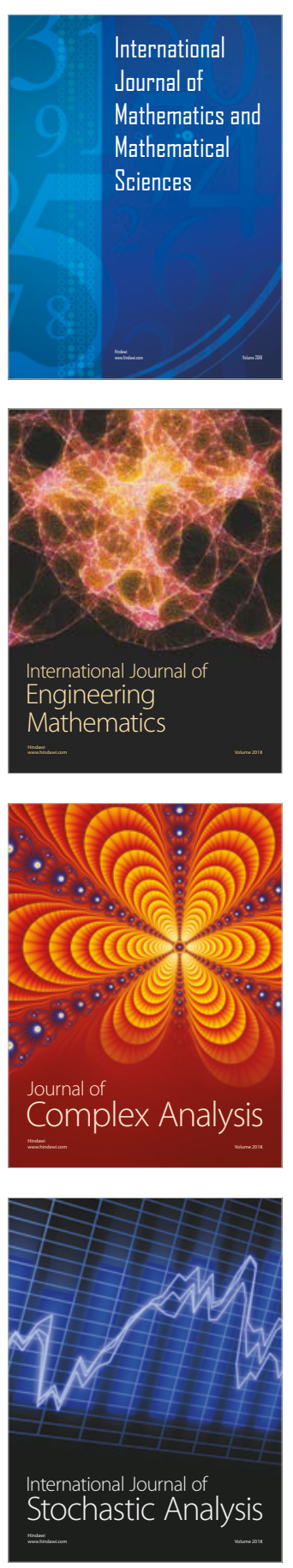
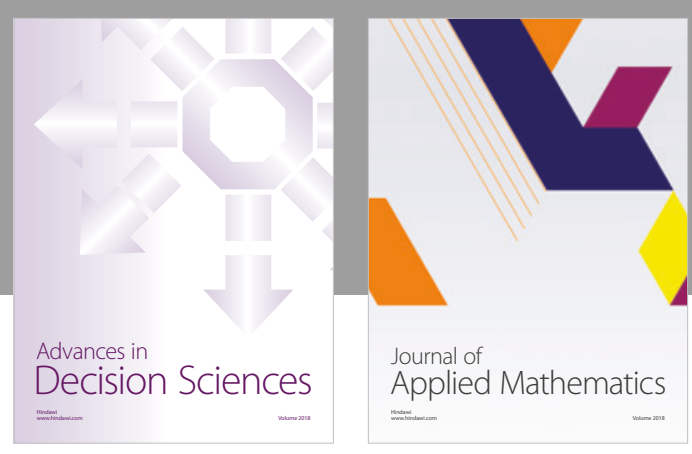

Journal of

Applied Mathematics
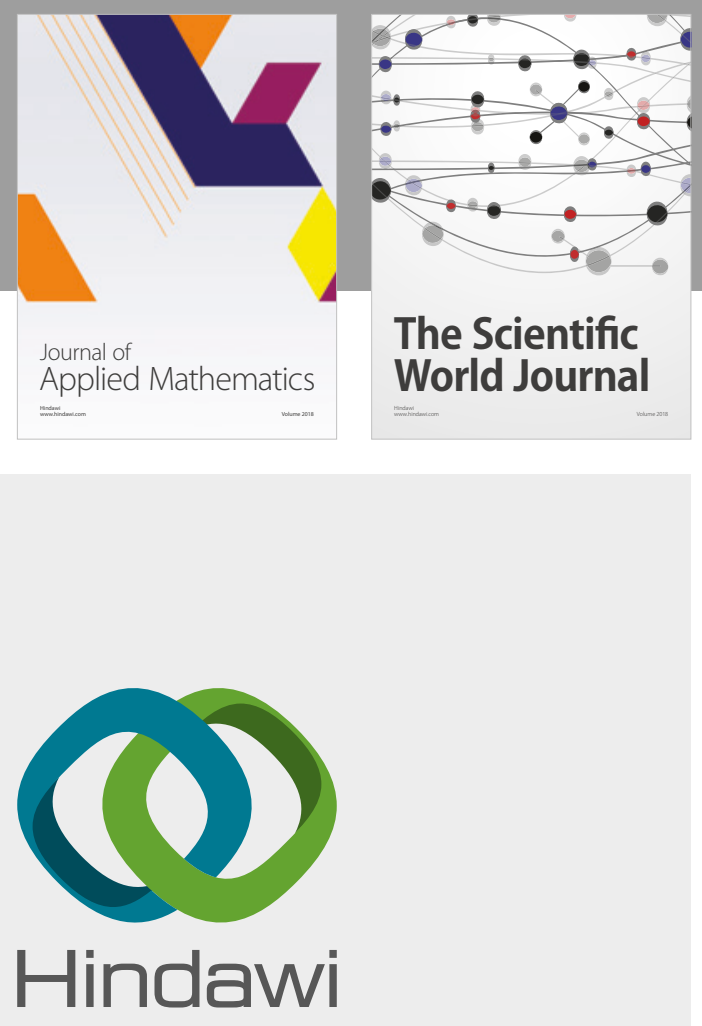

Submit your manuscripts at

www.hindawi.com

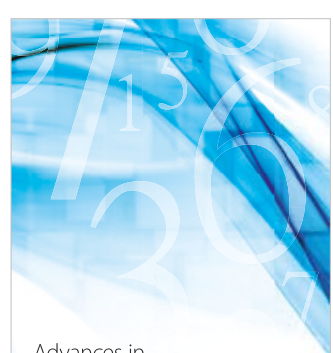

Advances in
Numerical Analysis
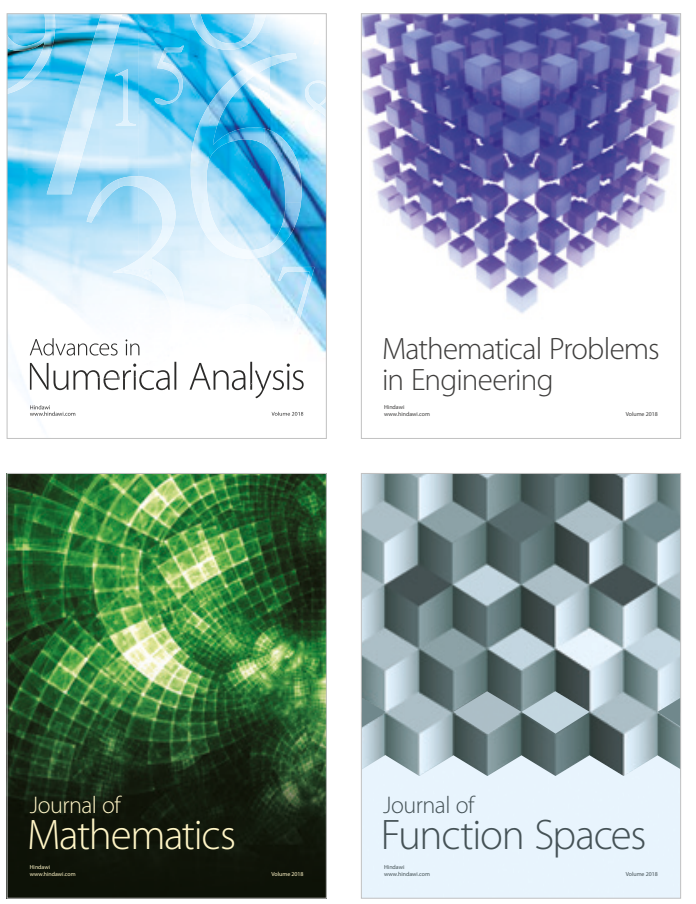

Mathematical Problems in Engineering

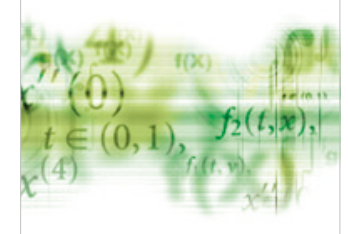

International Journal of

Differential Equations

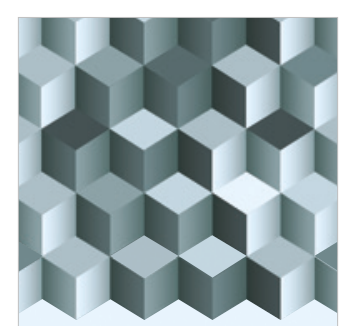

Journal of

Function Spaces

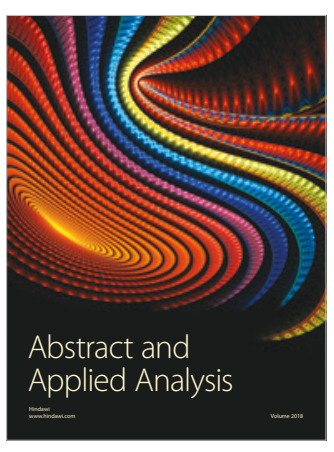

The Scientific

World Journal

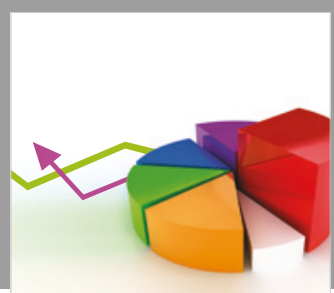

Journal of

Probability and Statistics
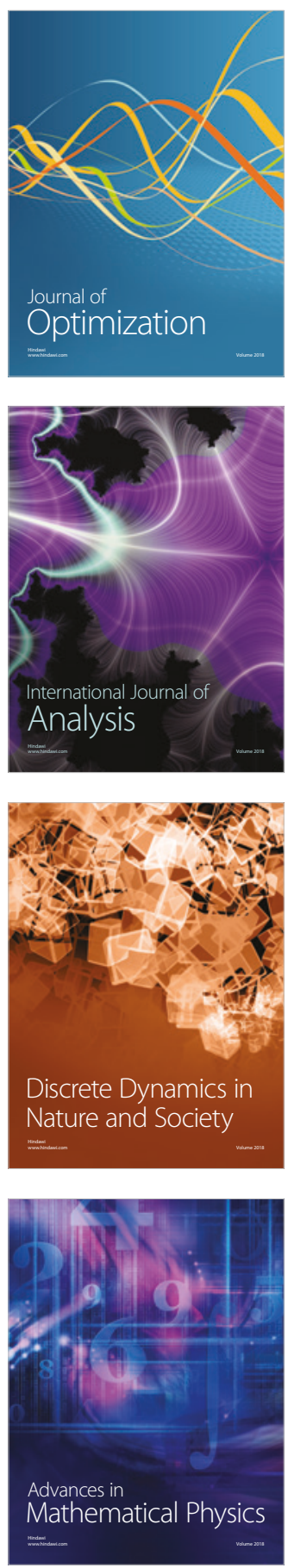